\title{
The MILC Chemical Abstracts Project
}

$I^{\mathrm{s}}$ N THE FALL OF 1953, a joint meeting of the participating librarians and the directors of the Midwest Inter-Library Center discussed goals for their cooperative enterprise and confirmed that a positive and forward-looking acquisitions program was essential to meeting the demands of research. ${ }^{1}$ One of the proposals relating to the acquisitions policy called for a high priority to be given to periodicals not held by the MILC member libraries. As an example, it was suggested that holdings recorded in such special lists as that issued by Chemical Abstracts be checked to ascertain wants in the region.

From this beginning has evolved the Center's Chemical Abstracts Project, the final step of which was taken on December $10,1956$.

The selection of the Chemical $A b$ stracts list $^{2}$ as a basis for this significant experiment in regional coverage may be ascribed to the following reasons:

1. All of the MILC member institutions have a strong interest in chemistry and related fields.

2. The Chemical Abstracts list provides a handy tool for a reasonably accurate locating of current subscriptions in member libraries, thus reducing substantially the extent of list-checking needed for identifying wants.

3. The Chemical Abstracts list is broad

1 For a statement of the Center's acquisitions policy and program, see CRL, XV (1954), 47-49, 89.

2 American Chemical Society. List of Periodicals $A b$. stracted by Chemical Abstracts, with Key to Library Files and Other Information. Columbus, Ohio, 1951. 255 p. New edition planned for publication in March 1957.

Mr. Esterquest is director, Midwest Inter-Library Center. in scope, including a large number of chemistry-related journals in technology, medicine, and the biological sciencesfields in which the MILC members have research programs - thus, a purpose is served that is not limited to chemistry in the narrow sense.

4. Although the Chemical Abstracts list includes an imposing number of titles -actually about 4,700 -it is still selective, since the editors apply known criteria for inclusion as a matter of policy. It can be assumed that, if the editors accept an abstract and list the parent journal, that journal is one that will be asked for in our libraries.

Preliminary checking of the Chemical Abstracts list took place during late 1953 and early 1954, with most of the labor contributed by Mr. Herman Henkle of the John Crerar Library. His June 1954 report to the MILC group included the following table, which showed the distribution of current subscriptions of Chemical Abstracts journals among member libraries:

$\begin{array}{cc}\text { Number of Titles } & \begin{array}{c}\text { Number of } \\ \text { Member Libraries } \\ \text { Having } \\ \text { Current Subscription }\end{array} \\ 1,583 & \text { none } \\ 651 & 1 \\ 425 & 2 \\ 300 & 3 \\ 228 & 4 \\ 206 & 5 \\ 196 & 6 \\ 169 & 7 \\ 148 & 8 \\ 134 & 9 \\ 117 & 10 \\ 114 & 11 \\ 92 & 12 \\ 94 & 13\end{array}$


Total 4,732
Mr. Henkle's report called particular attention to the total number of subscriptions, both duplicate and unique, held by MILC libraries, namely, 18,101. "This statistic," he said, "is particularly significant with reference to the 1,583 titles not held by any MILC library. It would require only 8.7 per cent change in the total subscription lists to gain complete coverage without increasing the total number of subscriptions maintained by member libraries."3 Although consideration was given to the possibility of a planned program of substitute subscriptions within member libraries, in order to increase the percentage of titles held by the group, this approach was not included in the program ultimately adopted on account of the extensive checking and reporting that would have been required.

Instead, it was decided that participating libraries would be free to cancel subscriptions to journals which later holdings information revealed to be widely held, and, conversely, to subscribe to others that were lacking or scarce in the region, merely reporting such decisions to the Center.

Following the Henkle report of June 1954, the MILC member librarians gave primary attention to the 1,583 periodicals not represented in any of their libraries in the form of a current subscription. The core of their decision was that these titles should be added as soon as possible and that member libraries should have the opportunity to add those of them which they might individually select.

\footnotetext{
3 "Final Report on Holdings of MILC Group of Libraries Recorded in List of Periodicals Abstracted by Chemical Abstracts, 1951." By Herman H. Henkle. June 4, 1954. Typewritten copy.
}

This decision to attempt "complete coverage," or "regional self-sufficiency," was based again on the first, third, and fourth reasons (cited above) for selecting the Chemical Abstracts list in the first place.

(At this stage, it was appropriate to remind ourselves that all the 4,732 listed periodicals are not to be found in the Columbus, Ohio, headquarters of Chemical Abstracts, since many abstracts are supplied by abstractors in various parts of the world who do not forward to the editorial office the journals containing the abstracted articles, nor does the Chemical Abstracts office receive these journals from other sources.)

As a next step, the Center furnished each member library with a photocopy of the Chemical Abstracts list, marked to show the 1,583 titles not recorded as coming to any of them. The member libraries checked these 1,583 titles and reported to the Center-

1. Those which they were in fact receiving regularly, even though the printed location key in the list did not so indicate.

2. Those which they would like to cancel.

3. Those to which they would like to enter new subscriptions.

The checked copies of the list were coded by the Center in a master copy, and the individual checked copies were returned to the member libraries with certain titles designated as follows:

"MAKE FIRM"-Those titles which the printed key or the subsequent checking indicated to be periodicals of which the checking library held the only subscription.

"sUBSCRIBE"- Those titles which the checking library offered to add and which would otherwise be lacking among the members.

The purpose of the "Make Firm" instruction was to call attention to unique titles and to designate these as requiring a higher than ordinary level of responsibility on the part of the sole subscribing library. Under this policy, the subscrib- 
ing library regards such a title as one to which it subscribes for the common welfare instead of for its own community alone, and thus it takes special pains to "make firm," i.e., to confirm that it is actually being received regularly and that its checking card shows that cancellation should take place only after consultation with the Center.

By December 1955 this portion of the task had been completed. Among the nineteen participating libraries, ${ }^{4}$ there were found at this stage to be 951 unique, or "Make Firm," titles, distributed as shown in the following table:

\begin{tabular}{|c|c|}
\hline Number & $f$ Unique Titles \\
\hline John Crerar & 393 \\
\hline Illinois & 148 \\
\hline Wisconsin & 77 \\
\hline Purdue & 56 \\
\hline Chicago & 51 \\
\hline Minnesota & 51 \\
\hline Wayne & 49 \\
\hline Iowa & 25 \\
\hline Kansas & 21 \\
\hline Northwestern & 19 \\
\hline Indiana & 18 \\
\hline Ohio & 15 \\
\hline Michigan State & 9 \\
\hline Indiana Medical & 2 \\
\hline Notre Dame & 5 \\
\hline Northwestern Medical & 4 \\
\hline Cincinnati & 2 \\
\hline Indiana Medical & 2 \\
\hline Illinois Institute of Technology & 1 \\
\hline Total & 951 \\
\hline
\end{tabular}

Indiana University Library and John Crerar led the list of those libraries which, at this time, entered 142 new subscriptions. These new subscriptions, plus those unrecorded subscriptions discovered by means of the checking procedure, reduced the number of "lacking" titles from the preliminary estimate of 1,583 to a reasonably accurate count of 837 .

There has been a historic interest in

\footnotetext{
${ }^{4}$ When this checking was being done there were sixteen members in MILC, to which were added the three off-campus medical libraries of Illinois, Indiana, and Northwestern. As of January 1957, there are
} eighteen MILC members. the profession in the degree of overlapping (i.e., duplication) among research library collections as related to the number and extent of identical lacunae, and, like the preliminary estimate of lacking chemical titles, this more exact count of 837 journals is worth noting. These 837 titles not being received by a single MILC member represent 18 per cent of the 4,732 in the Chemical Abstracts list. That one in six of these journals is not found in even one of these libraries would seem to be curious when one realizes that among the MILC membership are five million-volume libraries, and six libraries with book budgets in excess of $\$ 200,000$. It should be remembered too that an additional 20 per cent of these periodicals (951 of them) are being received by only one member library.

At a meeting of the member librarians in July 1955, it was agreed that it should be the Center itself that should enter subscriptions to the 837 lacking journals, rather than that they should be scattered among the members. This decision was based upon recognition of the fact that the titles in question were "less-used," and thus appropriate for MILC, and that existing Center machinery, as well as its location, made for relatively easy access. There is, furthermore, an often unrecognized advantage in having a cooperatively acquired item housed in the Center building. This has to do with what might be called "equality of access" among the members, since, in the case of the Center, there is no factor of local priority of use which must necessarily exist when an item is housed in a member library.

Although all the preliminary work was complete, the Chemical Abstracts project was put on ice from July 1955 until the summer of 1956 , while waiting for budget support for personnel. Meanwhile, the National Science Foundation became acquainted with the MILC plans and, last October, made a grant to support the project during its initial period.

(Continued on page 216) 